\title{
Sonographic Measurement of Fetal Ear Length in Turkish Women with a Normal Pregnancy
}

\author{
Mucize Eriç Özdemir ${ }^{1}$, Işıl Uzun ${ }^{2}$, Ayşe Karahasanoğlu ${ }^{1}$, Mehmet Aygün ${ }^{1}$, Hale Akın ${ }^{1}$, Fehmi Yazıcıoğlu ${ }^{1}$ \\ ${ }^{1}$ Department of Obstetrics and Gynecology, Süleymaniye Education and Research Hospital, İstanbul, Turkey \\ ${ }^{2}$ Department of Obstetrics and Gynecology, Bakırköy Acıbadem Hospital, İstanbul, Turkey
}

\begin{abstract}
Background: Abnormal fetal ear length is a feature of chromosomal disorders. Fetal ear length measurement is a simple measurement that can be obtained during ultrasonographic examinations.

Aims: To develop a nomogram for fetal ear length measurements in our population and investigate the correlation between fetal ear length, gestational age, and other standard fetal biometric measurements.

Study Design: Cohort study.

Methods: Ear lengths of the fetuses were measured in normal singleton pregnancies. The relationship between gestational age and fetal ear length in millimetres was analysed by simple linear regression. In addition, the correlation of fetal ear length measurements with biparietal diameter, head circumference, abdominal circumference, and femur length were evaluated.Ear length measurements were obtained from fetuses in 389 normal singleton pregnancies ranging between 16 and 28 weeks of gestation.
\end{abstract}

Results: A nomogram was developed by linear regression analysis of the parameters ear length and gestational age. Fetal ear length ( $\mathrm{mm})$ $=\mathrm{y}=(1.348 \mathrm{X}$ gestational age $)-12.265)$, where gestational ages is in weeks. A high correlation was found between fetal ear length and gestational age, and a significant correlation was also found between fetal ear length and the biparietal diameter $(r=0.962 ; \mathrm{p}<0.001)$. Similar correlations were found between fetal ear length and head circumference, and fetal ear length and femur length.

Conclusion: The results of this study provide a nomogram for fetal ear length. The study also demonstrates the relationship between ear length and other biometric measurements.

Key Words: Chromosomal disorders, fetal ear length, sonography
Abnormal fetal ear length is a feature of many chromosomal anomalies and aneuploidy conditions (1-3). In many studies, fetal ear length measurement has been identified as an additional marker for fetal chromosomal anomalies $(4,5)$.

Fetal ear length measurement is one that can be obtained during virtually all ultrasonographic examinations, from early in the second trimester of pregnancy until delivery. Moreover, ultrasound is a cheap and non-hazardous imaging modality. This provides the sonographer with a simple and effective means to assess fetal ear length, which is an additional marker for chromosomal anomalies.

There have been a few studies that have given prenatal standards for fetal ear length measurement $(5,6)$. However, the majority of these studies have focused on Western populations. In this cross-sectional study, we measured the ear lengths of fetuses of Turkish women with normal pregnancies between 16 and 28 weeks gestation, in order to build an intrauterine ear length nomogram of our population. Our aim was to help to define normal and abnormal fetal ear lengths, particularly in the Turkish population.

We hope that this specific nomogram will be better tailored to the Turkish population than the nomograms based on Western population data.

\section{MATERIAL AND METHODS}

Ear length measurements were obtained prospectively in 389 singleton fetuses of gestations between 16 and 28 weeks. All sonographic evaluations were performed between August 2009 and August 2010 in the prenatal diagnosis unit at the Süleymaniye Maternity Hospital using a Voluson 730 Expert machine (Voluson 730 ;General Electric, Tiefenbach, Austria) fitted with a 2-7 MHz convex abdominal probe. The study was

Address for Correspondence: Dr. Iş1 Uzun, Department of Obstetrics and Gynecology, Süleymaniye Education and Research Hospital, İstanbul, Turkey Phone: +905325141526 e-mail: isiluzu@gmail.com

Received: 17.06.2013 Accepted: 22.01.2014 • DOI: 10.5152/balkanmedj.2014.19784

Available at www.balkanmedicaljournal.org 
approved by the ethics committee of the institution. Written informed consent was obtained from each patient.

Cases with normal sonographic findings were included. Cases with sonographic abnormalities such as intrauterine growth retardation, structural anomalies, oligohydramnios, and polyhydramnios were excluded from the study. Patients with a history of chromosomal abnormality in previous offspring were also excluded from the study.

Gestational age was assessed using the woman's menstrual history in conjunction with ultrasonographic estimates of biparietal diameter, head circumference, abdominal circumference, and femur length according to established nomograms for these parameters. Women with unreliable menstrual histories were excluded from the study. Discrepancies between menstrual date and ultrasonographic gestational age were both accepted as exclusion criteria. In 21 patients (5.1\%), the fetal ear length could not be measured because of positional problems. Hence, the final study population comprised 389 healthy fetuses. After definition of the helix-lobe and the tragus, the maximum distance between the cranial tip of the helix and the caudal tip of the lobe was measured in the parasagittal view (Figure 1).

Fifteen fetuses were randomly measured by two different investigators to obtain inter-observer variability. Three measurements were taken in each case and the mean value of these was used in calculations.

The patients were divided into groups according to gestational age of the fetus. A single measurement at that gestational week was considered.

In addition to these measurements, a detailed anomaly scan was undertaken for each fetus. The relationship between gestational age and fetal ear length in millimetres was analysed using simple linear regression. On sonography, a regression model was constructed for ear length, with the best adjustments represented by a formula.

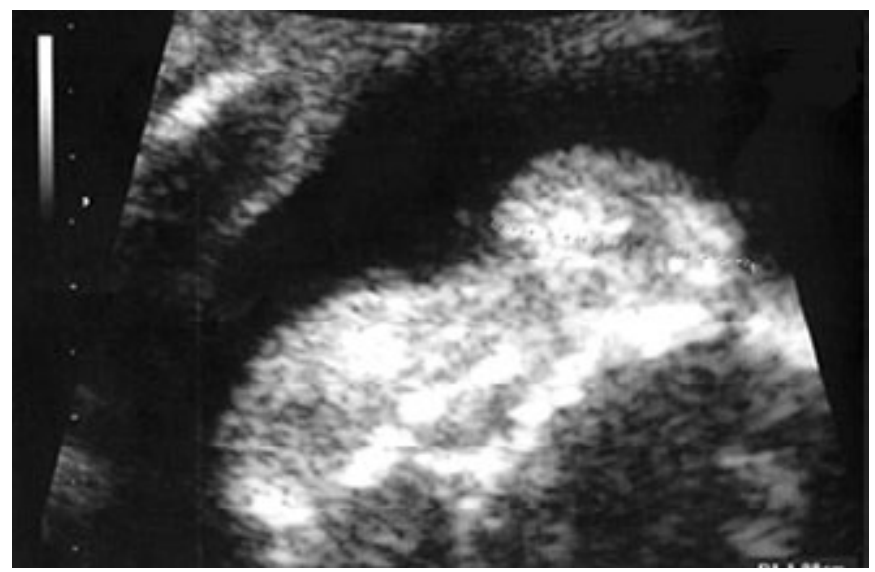

FIG. 1. Foetal ear length measurement
For a given gestational age, predicted values were obtained for the $5^{\text {th }}, 10^{\text {th }}, 25^{\text {th }}, 50^{\text {th }}, 70^{\text {th }}, 90^{\text {th }}$, and $95^{\text {th }}$ percentiles to develop the nomogram.

Statistical analyses were performed by the NCSS 2007 (NCSS; Utah, USA) pocket program. The association between fetal ear length (MoM and Z scores) and gestational age was calculated using regression analysis; thus, the percentile values were found. A 95\% confidence interval was used for the results. Pearson correlation analysis was used.

\section{RESULTS}

In total, 410 pregnant women were initially selected; however, 21 women were excluded because of an inability to obtain appropriate fetal ear measurements. Therefore, for the final statistical analysis, 389 pregnant women with normal pregnancies between 16 and 28 weeks gestation were included.

The mean maternal age \pm SD was $27.92 \pm 5.85$ years (range, 16-46 years). The mean gestational age was $22.9 \pm 3.78$ weeks (range, 16-28 weeks and 6 days).

The mean ear length increased from 9.59 \pm 1 (range, 8.20$11.60 \mathrm{~mm}$ ) in the $16^{\text {th }}$ week to $26.61 \pm 3.29$ (range, $17.60-31.90$ $\mathrm{mm}$ ) in the $23^{\text {rd }}$ week (Table 1 ).

A correlation was found between fetal ear length and gestational age. A regression model was constructed for ear length on ultrasound, with the best adjustments represented by the following equation: Fetal ear length $(\mathrm{mm})=\mathrm{y}=(1.348 \mathrm{X}$ gestational age ) -12.265), (Figure 2, Table 2).

TABLE 1. Descriptive analysis of ear length measurements at each gestational age interval

\begin{tabular}{lccc}
\hline $\begin{array}{l}\text { Gestational } \\
\text { age }\end{array}$ & Mean \pm SD & $\begin{array}{c}\text { Ear length }(\mathrm{mm}) \\
\text { Minimum }\end{array}$ & Maximum \\
\hline 16 & $9.59 \pm 1$ & 8.20 & 11.60 \\
17 & $10.07 \pm 1.33$ & 8.60 & 12.90 \\
18 & $11.82 \pm 1.6$ & 9.00 & 14.30 \\
19 & $12.98 \pm 1.52$ & 10.60 & 15.50 \\
20 & $16.1 \pm 1.53$ & 11.50 & 19.70 \\
21 & $16.62 \pm 1.69$ & 12.90 & 21.20 \\
22 & $17.45 \pm 1.27$ & 13.20 & 18.90 \\
23 & $18.26 \pm 1,76$ & 14.90 & 21.10 \\
24 & $19.47 \pm 1.77$ & 15.30 & 22.30 \\
25 & $21.93 \pm 2.16$ & 15.70 & 26.30 \\
26 & $21.69 \pm 2.17$ & 16.60 & 24.20 \\
27 & $24.41 \pm 1.6$ & 19.40 & 27.80 \\
28 & $26.61 \pm 3.29$ & 17.60 & 31.90 \\
\hline
\end{tabular}

SD: standard deviation 
A nomogram was obtained with the predicted values at 5 th, $10^{\text {th }}, 25^{\text {th }}, 50^{\text {th }}, 75^{\text {th }}, 90^{\text {th }}$, and $95^{\text {th }}$ percentiles (Table 3 ).

Correlations between fetal ear length and other biometric measurements (biparietal diameter, head circumference, and femur length) were also evaluated.

A significant correlation was found between fetal ear length and biparietal diameter $(\mathrm{r}=0.962, \mathrm{p}<0.001)$ (Table 4$)$. A similar correlation was found between fetal ear length and other parameters (head circumference and femur length) (Table 4).

Biparietal diameter/fetal ear length ratios were fairly constant between 16 and 28 weeks of gestation (Table 4).

\section{DISCUSSION}

A decade ago, sonographic markers of fetal karyotypic abnormalities were limited to major structural malformations. However, in recent years, several investigators have reported many detailed structural findings in the second and third trimester ultrasound evaluations, for identifying those fetuses with karyotypic abnormalities (7).

Ear length measurement as a marker of aneuploidies was first reported in a study published by Birnholz et al. (8). Many subsequent studies have agreed with the findings of Birnholz et al. $(5,9,10)$. Different investigators have used different cutoff points to define a "small ear" or "short ear" $(2,4,11,12)$. Sivan et al. (13) defined a "small ear" as having measurements

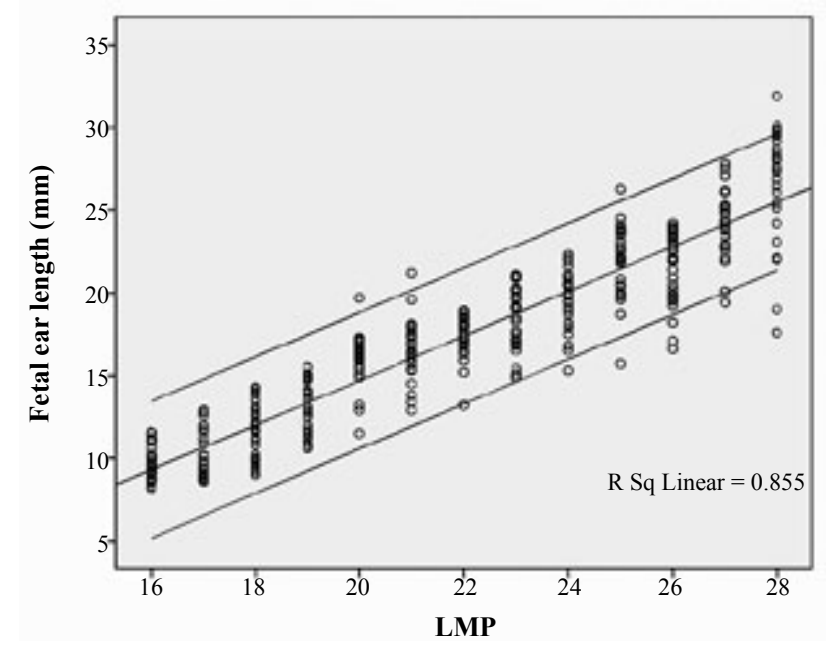

FIG. 2. Relationship between gestational age and foetal ear length $(R$ Square $=0.855$ ) less than the mean-2 SD. However, in general, it appears that a measurement in the $<5$ th percentile, or the $<10$ th percentile for gestational age is a reasonable cut-off value for screening fetuses for chromosomal abnormalities.

Reported studies suggest that short ear length measurements alone can possibly detect one-third or more of all fetuses with significant aneuploidies. The prevalence of short ear length for Trisomy 13 and Trisomy 18 would be much higher $(2,4,6,10,12)$. Chitkara et al. (12) reported that $32.3 \%$ of fetuses in their study presenting with chromosomal abnormalities had short ear lengths. Among all fetuses with significant chromosomal abnormalities, six (17.6\%) fetuses showed no other structural abnormalities apart from short ear length (5). In the study reported by Shimizu et al., the predictive value of ear length measurement was similar to or better than that of the nuchal fold. However, there are questions regarding the validity of this ratio in cases of Trisomy 21 and Trisomy 18 with growth retardation $(3,14)$. An abnormally small ear is associated with chromosomal abnormalities as well as with other structural abnormalities (15). Studies of live newborn infants and autopsies from second and third trimester fetuses have shown a significant correlation between small ears and Trisomy 21 and other chromosomal abnormalities $(1,16)$.

All of these findings have prompted many investigators to use abnormal ear length measurement as an additional marker in the detection of these anomalies.

Ear length in normal fetuses has also been measured in many studies $(6,7,9,17)$. These studies are mostly based on Western populations. Our study was based on the Turkish population, and our findings suggest that there is a linear relationship between fetal ear length and gestational age. This result is consistent with other studies.

We have formulated a nomogram for a Turkish population sample, which shows that fetal ear length in the Turkish population is similar to that of the Western population. The $50^{\text {th }}$ percentile for fetal ear length at 24 weeks gestation was $19.80 \mathrm{~mm}$ in our study and was $20 \mathrm{~mm}$ in the study reported by Yeo et al. (11). The relationship between ear length and biometric parameters (biparietal diameter, head circumference, and femur length) was also comparable with previous studies $(7,14,18)$. We observed that the ratio between biparietal diameter and fetal ear length were fairly constant between 16 and 23 weeks gestation. This means that there is a uniform growth pattern of these parameters.

TABLE 2. Summary of relationship of fetal ear length and gestational week

\begin{tabular}{lllcc}
\hline Y axis & X axis & Regression formula & Correlation Coefficient $(\mathrm{r})$ & $\mathrm{R}$ square \\
\hline Fetal ear length & LMP & $\mathrm{y}=(1.348$ X Gestation Age $)-12.265$ & 0.925 & 0.855 \\
\hline LMP: last menstrual period & &
\end{tabular}


TABLE 3. Fetal ear length percentiles by GA

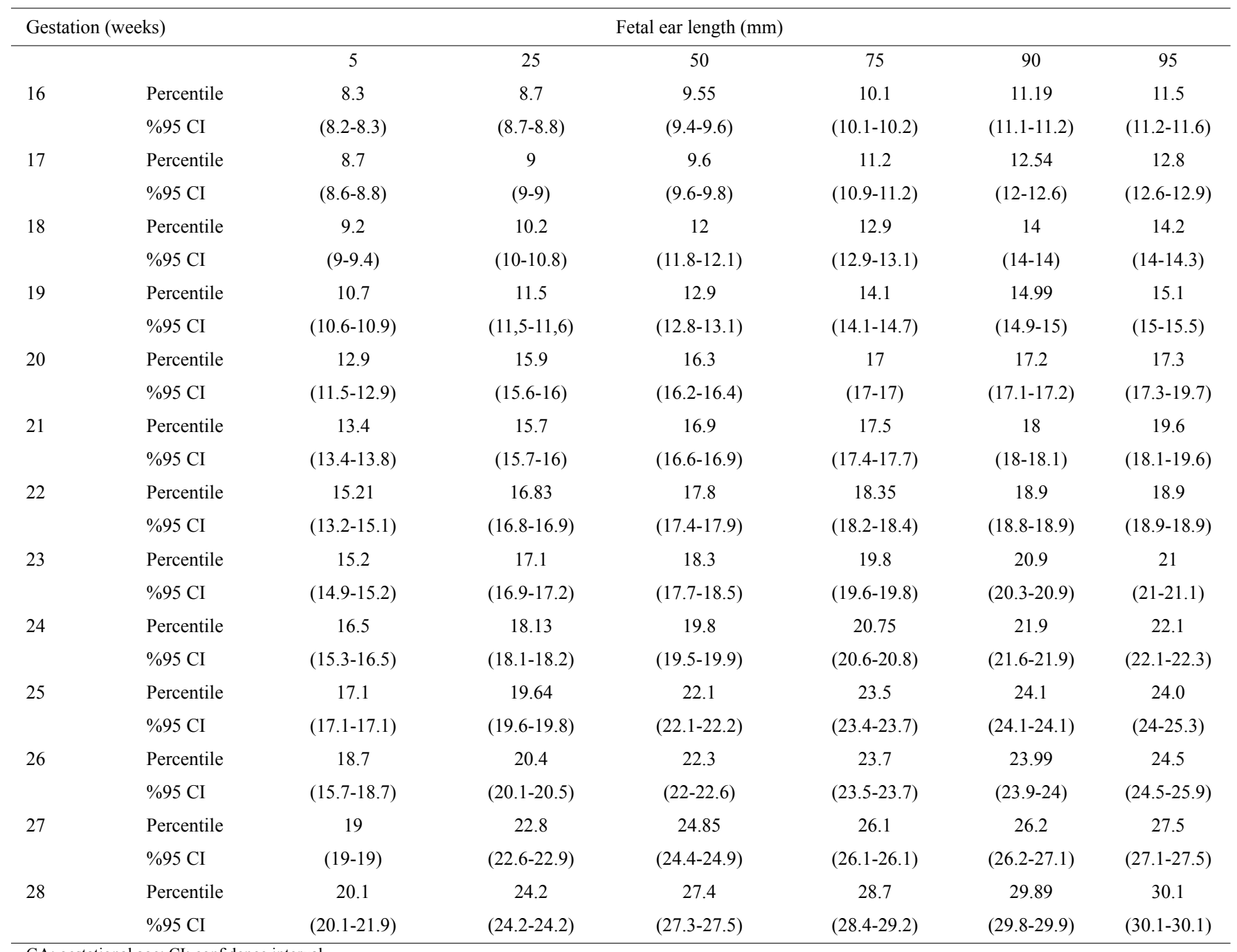

GA: gestational age; $\mathrm{CI}$ : confidence interval

TABLE 4. Summary of relationship of fetal ear length and BPD, HC and FL

\begin{tabular}{llll}
\hline Y axis & X axis & Regression formula & $\begin{array}{l}\text { Correlation } \\
\text { coefficient }(\mathrm{r})\end{array}$ \\
\hline Fetal ear length & BPD & $\mathrm{y}=(0.390$ X BPD $)-3.772$ & 0.962 \\
& HC & $\mathrm{y}=(0.109$ X HC $)-3.862$ & 0.958 \\
& FL & $\mathrm{y}=(0.474$ X FL $)-0.175$ & 0.961 \\
\hline
\end{tabular}

BPD: biparietal diameter; HC: head circumference; FL: femur length

Antenatal evaluation of fetal ear length may be useful for the detection of various congenital anomalies, including chromosomal abnormalities and several other structural abnormalities. Therefore, we have developed a nomogram for our population to detect deviations in fetal ear length that will help to provide better detection rates for aneuploidy in the Turkish population.
Ethics Committee Approval: Ethics committee approval was received for this study.

Informed Consent: Written informed consent was obtained from patients who participated in this study.

Peer-review: Externally peer-reviewed.

Author contributions: Concept - M.E.Ö., F.Y., M.A.; Design - M.E.Ö., F.Y., A.K.; Supervision - F.Y., M.Ö., H.A.; Resource - M.E.Ö., F.Y., I.U.; Materials - F.Y., M.Ö., M.A.; Data Collection\&/or Processing - M.Ö., F.Y., A.K.; Analysis\&/or Interpretation - M. Ö, F.Y., H.A.; Literature Search M.Ö., I.U., F.Y.; Writing - I.U., M.Ö., F.Y.; Critical Reviews - F.Y., I.U., M.Ö.

Conflict of Interest: No conflict of interest was declared by the authors.

Financial Disclosure: The authors declared that this study has received no financial support. 


\section{REFERENCES}

1. Aase JM, Wilson AC, Smith DW. Small ear in Down's syndrome: A helpful diagnostic aid. J Pediatr 1973;82:845-7.[CrossRef]

2. Lettieri L, Rodis JF, Vintzileos AM, Feeney L, Ciarleglio L, Craffey A. Ear length in second-trimester aneuploid fetuses. Obstet Gynecol 1993;81:57-60.

3. Nyberg DA, Kramer D, Resta RG, Kapur R, Mahony BS, Luthy DA, et al. Prenatal sonographic findings of trisomy 18: Review of 47 cases. $J$ Ultrasound Med 1993;12:103-13.

4. Awward JT, Azar GB, Karam KS, Nicolaides KH. Ear length: A potential sonographic marker for Down syndrome. Int J Gynecol Obstet 1994;44:233-8.[CrossRef]

5. Chitkara U, Lee L, Oehlert JW, Bloch DA, Holbrook RH, El-Sayed YY, et al. Fetal ear length measurement: a useful predictor of aneuploidy? Ultrasound Obstet Gynecol 2002;19:131-5.[CrossRef]

6. Shimizu T, Salvador L, Allanson J, Hughes-Benzie R, Nimrod C. Ultrasonographic measurement of fetal ear. Obstet Gynecol 1992;80:381-4.

7. Nicolaides K, Shawwa L, Brizot N,Sijders R. Ultrasonographically detectable markers of fetal chromosoml defects . Ultrasound Obstet Gynecol 1993;3:56-69.[CrossRef]

8. Birnholz JC, Farrell EE. Fetal ear length. Pediatrics 1988;81:555-8.

9. Lettieri L, Rodis JF, Vintzileos AM, Feeney L, Ciarleglio L, Craffey A. Ear length in second-trimester aneuploid fetuses. Obstet Gynecol 1993;81:57-60.
10. Yeo L, Guanan ER, Day-Salvatore DL, Vintzileos AM, Walres C. Prenatal detection of fetal aneuploidy using sonographic ear length. Am J Obstet Gynecol 1998:178:141.

11. Yeo L, Guzman ER, Ananth CV, Walters C, Salvatore DD, Vintzileos AM. Prenatal detection of fetal aneuploidy by sonographic ear length. $J$ Ultrasound Med 2003;22:565-76.

12. Shimizu T, Salvador L, Hughes-Benzie R, Dawson L, Nimrod C, Allanson J. The role of reduced ear size in the prenatal detection of chromosomal abnormalities. Prenat Diagn 1997;17:545-9.[CrossRef]

13. Sivan Y, Merlob P, Reisner SH. Assessment of ear length and low set ears in newborn infants. J Med Genet 1983;20:213-5.[CrossRef]

14. Kurjak A,Kirkinen P.Ultrasonographic growth patterns of fetuses with chromosomal aberrarions. Acta Obs Gynecol Scand 1982:61:223-5. [CrossRef]

15. Hutchinson JC Jr, Caldarelli DD, Gould HJ. Classification and multidisciplinary management of microtia. Otolaryngol Clin North Am 1981;14:855-87.

16. Allanson JE, O'Hara P, Farkas LG, Nair RC. Anthropometric craniofacial pattern profiles in Down syndrome. Am J Med Genet 1983:20: 213-5.

17. Chitkara U, Lee L, El-Sayed YY, Holbrook RH, Bloch DA, Oehlert JW, et al. Ultrasonographic ear length measurement in normal second- and thirdtrimester fetuses. Am J Obstet Gynecol 2000;183:230-4. [CrossRef]

18. Joshi KS,Chawla CD, Karki S, Shrestsa NC. Sonographic measurement of fetal pinna length in normal Pregnancies. Kathmandu Univ Med J (KUMJ) 2011;9:49-53. 